$\xi=-1$

\title{
Electromagnetic Flux Analysis of Ds Hesfm for Directly Driven Actuator Used in Aircraft Applications
}

\author{
H. A. Soomro ${ }^{1 *}$, E. Sulaiman ${ }^{2}$, M. Jenal ${ }^{3}$, M. F. Omar ${ }^{4}$, L. I. Jusoh, S.K. Rahimi ${ }^{5}$ \\ 1,2,3,4,5 Department of Electrical Power Engineering, \\ Universiti Tun Hussien Onn Malaysia, 86400 Parit Raja \\ *Corresponding author E-mail: engg.hassansoomro@gmail.com.
}

\begin{abstract}
This paper presents the electromagnetic flux analysis of dual stator hybrid excitation switched flux machines (DS HESFM) using segmental rotor for the directly driven electromechanical actuator aimed to use in aerospace applications. The advantage of designing a machine with directly driven system is to eliminate the intermediate gear box system with having minor component count and reduced jamming possibility. The proposed design of DS hybrid excitation with high torque density is investigated in this paper as a potential solution for aircraft applications. The key intentions of the design are high level of actuator integration to reduce the overall weight and volume and fault tolerance ability. The proposed design of DS HESFSM has simple structure, which consist of only six field excitation coils (FECs) housed in outer stator along with six armature coils (ACs) whereas, six permanent magnets (PMs) are positioned in the inner stator. Moreover, DS HESFM structure is analyzed at open circuit and short circuit conditions conditions by means of "commercial 2D FEA package, JMAG-designer ver. 14.0," released by JSOL Corporation.
\end{abstract}

Keywords: Electromagnetic Flux; Flux Switching; Hybrid Excitation; Segmental Rotor; Torque Analysis.

\section{Introduction}

In recent, the modern aircrafts system is being transferred toward a more electric actuation (MEA) based generation and delivery systems, which increase the drive towards electrical loads. Actuator supplied by means of electric energy gives the diverse advantage of eliminating out the hydraulic supply with all its associated disadvantages. Generally, electrically supplied actuators are divided into two types of systems such as electrohydraulic actuators (EHAs) and electromechanical actuators (EMAs). EHAs uses a flexible speed pump supplying which supplies a local hydraulic actuation scheme, while, EMAs uses an adjustable speed electrical motor drive attached to a ball or else roller screw over a gearbox. Though, (EMAs) offer a overall leakage free and better solution, (EHAs) are frequently favored to EMAs in safety critical applications owing to the problem of probable mechanical jams in (EMAs). The jamming concern with EMAs is currently being researched from both the material-surface property point of view along with finding safe and effective approaches to make the system free jammed EMA from the flight surface. Electrical machines are an enabling machinery in decreasing the chance of an EMA jamming [1-2].

As defined in [3], the usage of concentrated wound stator motor with high number of poles is directly connected to a roller screw actuator which creates high power density. Also, at a specified power, the size of the machine will be smaller as the higher speed of the machine.

On the other hand, "the gear ratio and the size of the gearbox will be increased. To use the high number of poles, the active rotor magnetic material decreases, leaving a hollow space in the center of the machine which has the benefit to minimize the probability of jamming and consequently rise the reliability of the actuation system. It was more revealed that, by using such winding configuration, it is possible to advance the degree of fault tolerance of the electrical motor by having magnetically decoupled windings to permit for the active control of the machine under numerous faulted conditions and thus refining the degree of reliability" [4].

\section{Machine Design Concerns for Aircraft Ac- tuation Drive}

The elementary requirements to be considered for any aircraft actuation drive systems are smallest size, lowest weight, and costs to attain the essential performances. Besides, the consideration and the number of backup actuators chosen for fault tolerance and reliability, depending on the flight surface [5].

Efficiently, Fault tolerance can be achieved by redundant drive components. This can also be realized by doubling or tripling the drive systems or, to have independent redundant systems with the number of duplicates depending on the reliability of the particular component. In any fault tolerant topology, it is therefore important to make each system isolated from the others to minimize the possibility of any common failure. From approach of an electrical drive, it is claimed that the electrical machine itself can be a fault tolerant up to a certain degree without having a duplicate one. This is usually can be attained by designing machines to function with short-circuit and open-circuit faults conditions. "This is done by means of multiphase machines and confirming that the phase windings and the power electronics supplying them are magnetically, electrically, and physically decoupled" [6-8].

However, there is foremost disadvantage of machine with multiphase is the duplication of the power and control electronics systems, which show a low consistency and reliability. Besides, satis- 
factory fault detection techniques are needed to detect and subsequently trigger the post fault control technique [9-10].

On the other hand, machines which are"sinusoidaly excited are generally preferred due to the compatibility with matrix converters which give different benefits mainly due to the elimination of the dc link and the unreliable electrolytic capacitors [11]

However, sinusoidally excited machines are seen as not being fault tolerant in their traditional form due to the high magnetic and physical coupling of their phase"windings. Whereas, nonsinusoidally excited machines have possible to be more fault tolerant but are not practical to be used with a matrix converter due to the resultant supply current distortion. [12].

\section{Machine Design and Specification of Pro- posed DS HESFM}

The machine has to encounter all the transient and steady state conditions by keeping the machine dimension to a minimum rang. The size of the machine is primarily limited by physical measurement restrictions, the loading characteristics, and the temperature range of the actuator should be able to operate in. Furthermore, the proposed structure of DS HESFM is illustrated in Figure 1, the proposed DS HESFM with three phase winding containing two stators. The outer rotor contains six armature coils housed in alternatively directions. Whereas, six field excitation coils (FECs) are housed in outer stator for the easy injection of DC excitation, maintenance and easy replacement in case of coil damage or fault. Besides, inner stator contains six slots inside the motor which comprises of six PMs at the surface of stator slots.

Moreover, segmental rotor contains ten rotor segments which is sandwiched between the outer and inner stator. Segmental rotor of the proposed motor gain the interest due to the reason of shortest path of magnetic flux flow from outer stator to inner stator and confirm the high performance of electromagnetic flux and torque performance.

Furthermore, the main design geometry, plus limitation stipulations of the"projected dual stator (DS FM) using hybrid excitations are arranged in Table I. The weight of the PM for proposed structure is fixed at $1 \mathrm{~kg}$. The basic sensitive parameters of the proposed design classified into two groups such as those linked to stators core and rotor core. On the stator core, it is again divided into three sets which are the FEC slot shape, armature slot shape, and PM in (inner stator) which is situated on the surface of the inner stator poles. The stators sensitive parameters are the outer stator radius (D1), inner stator radius (D2), and PM width (D3) Although, for the FEC slot parameters are FEC coil height and FEC coil width, (D4) and (D5) correspondingly. In case of armature coil, the armature coil parameters presented are armature coil height (D6) and the armature coil width (D7). Lastly, the segmental rotor parameters comprises, rotor radius (D8), rotor width (D9) and span angle (D10) of segment. These stated sensitive design free parameters, from D1 to D10 are confirmed in figure 2. In this research, the initial basic design parameters of the proposed initial DS HESFM using segmental rotor are"represented in Table 2.

Table 1: Design parameters and specifications

\begin{tabular}{|c|c|}
\hline Items & $\begin{array}{c}\text { DS HESFM with } \\
\text { segmental rotor }\end{array}$ \\
\hline Max. DC-bus voltage for inverter (V) & 650 \\
\hline Max. inverter current (Arms) & 360 \\
\hline $\begin{array}{c}\text { Max. current density in armature coil, Ja } \\
\text { (Arms/mm2) }\end{array}$ & 10 \\
\hline Max. current density in FEC, Je (A/mm2) & 10 \\
\hline Diameter of outer stator (mm) & 273 \\
\hline Diameter of inner stator (mm) & 131 \\
\hline Number of rotor segments & 10 \\
\hline Back iron length of outer stator (mm) & 20 \\
\hline Stator tooth width (mm) & 11 \\
\hline \multicolumn{2}{|c}{} \\
\hline
\end{tabular}

\begin{tabular}{|c|c|}
\hline Armature slot area $\left(\mathrm{mm}^{2}\right)$ & 526 \\
\hline FEC slot area $\left(\mathrm{mm}^{2}\right)$ & 526 \\
\hline Air gap length $(\mathrm{mm})$ & 0.5 \\
\hline Span of segments (degree) & $30^{\circ}$ \\
\hline Number of turns per slot of FEC & 10 \\
\hline Number of turns per armature coil (AC) slot & 10 \\
\hline
\end{tabular}

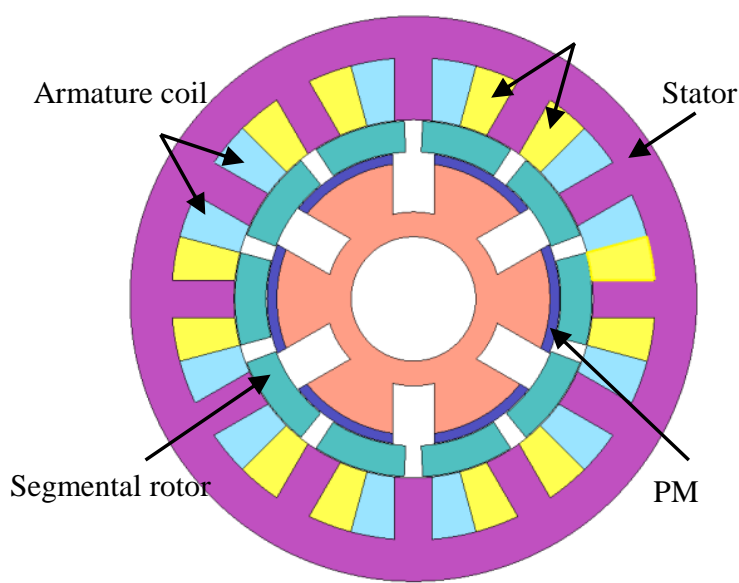

Fig.1: Initial design of proposed DS HESFM with segmental rotor

\section{Investigation of Operating Principles of DS HEFSM}

To investigate the operating principles of DS HESFM, a coil test is performed for each phase on the basis of 2-D FEA analysis. Coil"test is achieved at no load condition to authenticate the operating principle of a machine and the arrangement of armature coils in their specific slots. Initially, six coil analysis is performed. From six coil test, two coils will give identical patterns. The successful arrangement of armature coil directions and FECs direction the initial design is shown in figure 2 , whereas the sinusoidal three phase waveform of $\mathrm{U}, \mathrm{V}$ and $\mathrm{W}$, is shown in figure 3 , which validate the operation principle"of proposed DS HEFSM.

Table 2: Initial Design Parameters of proposed HESFM

\begin{tabular}{|c|c|c|}
\hline Parameters & Descriptions & $\begin{array}{c}\text { Initial design DS } \\
\text { HESFM }\end{array}$ \\
\hline D1 & Outer stator radius (mm) & 136.5 \\
\hline D2 & $\begin{array}{c}\text { Inverter current (Max) } \\
\text { (Arms) }\end{array}$ & 360 \\
\hline D3 & Width of PM (mm) & 7.43 \\
\hline D4 & Height of FEC coil (mm) & 30 \\
\hline D5 & Width of FEC coil (mm) & 21.4 \\
\hline D6 & $\begin{array}{c}\text { Height of armature coil } \\
\text { (mm) }\end{array}$ & 30 \\
\hline D7 & $\begin{array}{c}\text { Width of armature coil } \\
\text { (mm) }\end{array}$ & 21.4 \\
\hline D8 & $\begin{array}{c}\text { Radius of rotor segments } \\
\text { (mm) }\end{array}$ & 86 \\
\hline D9 & $\begin{array}{c}\text { Width of rotor segments } \\
(\mathrm{mm})\end{array}$ \\
\hline D10 & Span angle (degree) & 15 \\
\hline & & 526 \\
\hline
\end{tabular}

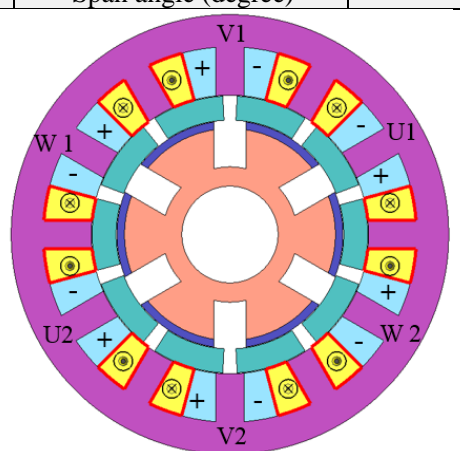

Fig. 2: Arrangement of armature coil and FECs 


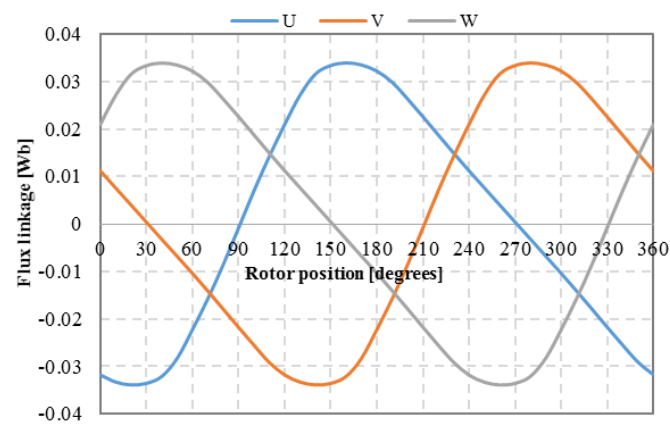

Fig. 3: Three phase U, V and W flux in armature coil

\section{Performance Analyses}

At no load condition, the armature current density Ja applied is zero for initial design while to energize the FE coil, the maximum current density Je of $7 \mathrm{~A} / \mathrm{mm}^{2}$ is injected to the initial HEFSM. At no load, the FEC and PM are main sources to produce flux linkage separately on outer and inner stator respectively.

\subsection{Induced EMF of initial DS HEFSM}

Figure. 4 illustrate the initial performances of induced emf of the proposed DS HESFM motor under no load condition at 500rpm. The amplitude of induced voltage produced from the flux of PM only is $26.5 \mathrm{~V}$ with some distortion in sinusoidal waveform as depicted in figure 4.

However, the induced voltage is generated by FE only is lesser as compared to PM, however there are still distortion in the waveform. While, by adding both sources (PM and FE) the amplitude is raised to almost $35 \mathrm{~V}$ due to the reason of field intensification effect by the addition of both sources. Although, from the figure it can be seen that the distortion has been reduced and confirms that the proposed DS HEFSM motor work under safe region smoothly displays apparently that the both active sources (PM plus FEC) once joined can cause the generation of more flux linkage as well as authenticate that the both fluxes are combined correctly.

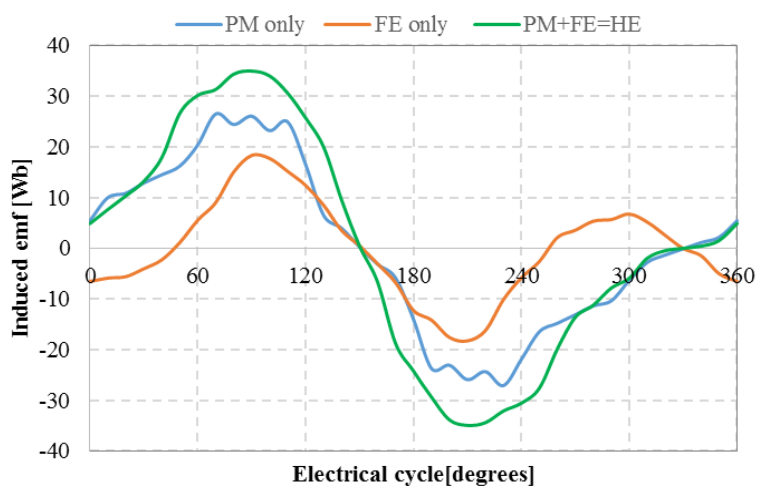

Fig. 4: Induced Emf of initial DS HEFSM

\subsection{Cogging torque of initial DS HESFM}

Initially, the performance of cogging torque for proposed DS HESFM has been examined at no load circumstance and shown in figure 5. From figure, it can be understood that the value of cogging torque at PM only is approximately $5.57 \mathrm{Nm}$ peak to peak. While, in case of FE only, the maximum filed current density of 7 $\mathrm{A} / \mathrm{mm}^{2}$ is applied to the filed coil. The cogging torque value in case of FE only appeared is high due to the high current in the FE coil which can cause the vibrations and acoustic noises in the motor.
On the other hand when both excitations are combined at no load conditions the cogging torque value has been reduced to some amount and produced moderate value of approximately $12 \mathrm{Nm}$ peak to peak. Although, initially the cogging torque of proposed design is higher than the case of only PM but its value is acceptable because the cogging torque should not be greater than the $10 \%$ of average torque.

The initial design of proposed DS HEFSM confirms that, at the maximum speed the motor performance will be smooth with less vibrations and noises which can enhance the efficiency of the motor.

Fig. 5: Cogging torque of initial DS HEFSM

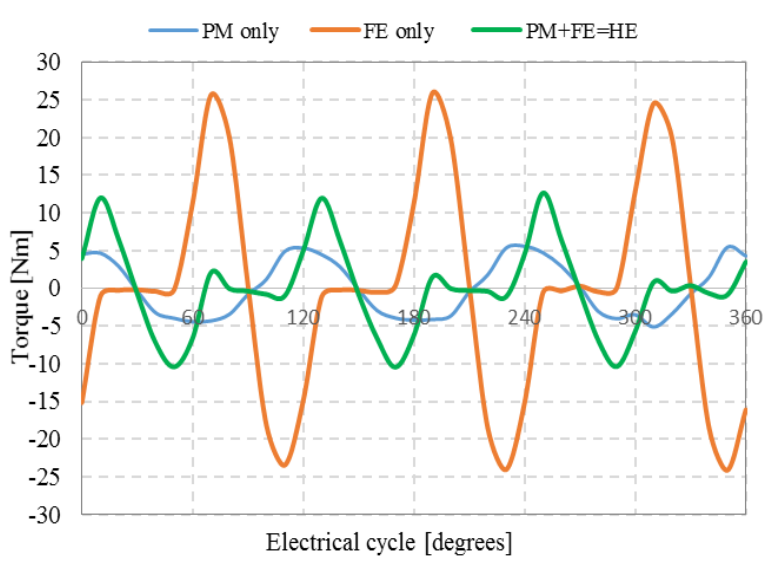

\subsection{Electromagnetic flux analysis of initial DS HEFSM}

The generated electromagnetic magnetic flux lines and magnetic flux distribution of proposed design of initial DS HESFM are also performed at no load or open circuit condition to examine the electromagnetic flux pattern and flux lines flow on the inner and outer stators respectively and then to rotor. Figure 6 and Figure 7, illustrate the electromagnetic flux lines produced and electromagnetic flux distribution of proposed design at open circuit condition $(\mathrm{Ja}=0)$, while, the maximum field current density of $7 \mathrm{~A} / \mathrm{mm}^{2}$ is inserted in the FE coil. From figure. 6, it is understandable that the electromagnetic flux lines are suitably and constantly flowing through stators to and then pass through the rotor segments deprived of much cancellation as well as leakage. Henceforth, making appropriate and short completed cycles. From figure 6, it is also obvious that the flux created by both the sources is completely circulated over the inner stator whereas for outer stator there are some unfilled spaces at back iron length. Though, generally flux circulation is satisfactory to produce higher torque performances. Alternatively, from figure 7 , it is clear that the electromagnetic flux is "thoroughly dispersed over the inner stator because of the PMs, which are situated on the inner stator. While, in the outer stator electromagnetic flux of $70 \%$ is circulated successfully leaving behind $30 \%$ of empty spaces on the stator as revealed in red circles due to formation of flux saturation at the stator pole tips and leakage. Moreover, from figure 7 , it is clear that maximum and"minimum flux density achieved in DS HESFM is 2.9T and 3.6E-05 $\mathrm{T}$ correspondingly.

Additionally, in case of "aircraft applications proposed DS HESFM design appears to be the best design to achieve better flux distribution and flux density presentations with minimum flux leakage plus saturations. Moreover, flux lines examination authenticate that the flux cancellations are also negligible which can be favourable for high speed applications". 


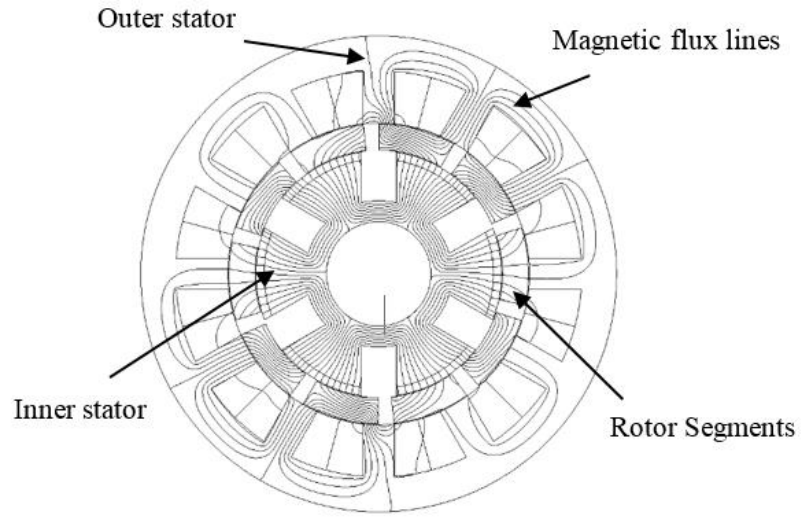

Fig. 6: Magnetic flux lines of DS HESFM

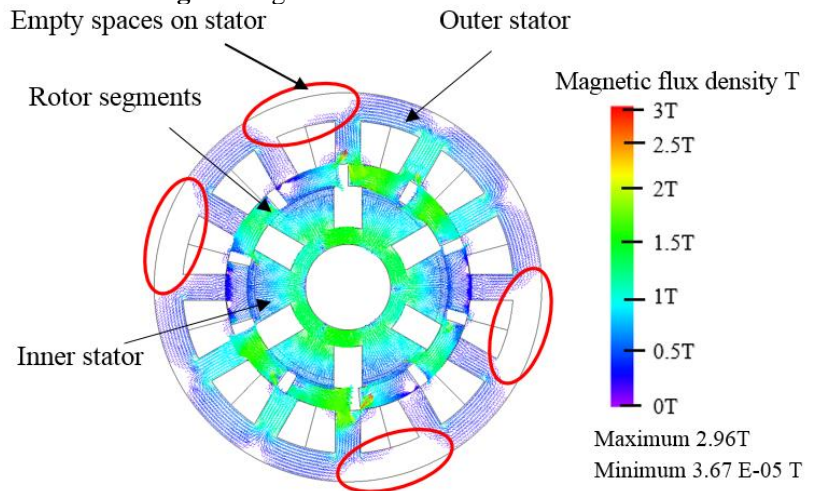

Fig. 7: Magnetic flux distribution of DS HESFM

\section{Analysis of Initial Design at Short Circuit}

Performance of proposed DS HESFM is analysed at short circuit by supplying maximum armature current density of $7 \mathrm{Arms} / \mathrm{mm}^{2}$. At different load conditions from $\mathrm{Ja} 7 \mathrm{Arms} / \mathrm{mm}^{2}$ to $\mathrm{Ja} 1$ Arms $/ \mathrm{mm}^{2}$, the performance of the motor is examined by applying both the excitation sources. In load analysis torque and power vs. field current density Je at different armature current density Ja, torque/power vs. speed characteristics are also examined

\subsection{Torque analysis at several field and armature cur- rent densities current density (je) of $7 \mathbf{a} / \mathrm{mm}^{2}$}

Torque investigation of the proposed DS HESFM with segmented rotor has been carried out at different loads by supplying different armature"current densities from zero to $7 \mathrm{Arms} / \mathrm{mm}^{2}$. Hereafter, at maximum field current density of $7 \mathrm{~A} / \mathrm{mm}^{2}$, the torque has been examined at different armature current densities (Ja) such as at $1 \mathrm{Arms} / \mathrm{mm}^{2}, 3 \mathrm{Arms} / \mathrm{mm}^{2}, 5 \mathrm{Arms} / \mathrm{mm}^{2}$, and $7 \mathrm{Arms} / \mathrm{mm}^{2}$. As a flux source, PM produces constant flux in the inner stator.

Whereas, the field current density is varied"by varies the current density Je, to inspect the torque behaviour at different loads. Figure 8 shows the torque inquiry at different armature current densities for various injected currents. From the figure it is obvious that at zero field current density there is some torque value which is due to the constant flux production of PMs. Due to PMs, torque achieved is produced. Furthermore, as the current density is increased the value of torque is also increased which verifies that the magnetic flux produced by increasing the FE current is properly added with flux of PMs. Which also endorse that the proposed structure is capable to produce more torque at higher loads. Although the pattern of graph is not showing enough increment in the torque value due the weak fluxes of FE coil in the outer stator which can be seen in Figure 7 .

Furthermore, from Figure 8, it can be"realized that at maximum armature current density of $7 \mathrm{Arms} / \mathrm{mm}^{2}$ the torque attained is almost $87.54 \mathrm{Nm}$, which is observably suitable for the airplane applications. Whereas minimum torque attained is at minimum armature current density of $1 \mathrm{Arms} / \mathrm{mm}^{2}$. Besides, linear pattern of torque shows that DS HE FSM structure has still tendency to survive the more flux deprived of saturation and cancellations'of fluxes. For aircraft applications where it is necessary for electric motors to achieve high torques especially at lower elevations and lower speeds, DS HESFM is accomplished to achieve required performances. Subsequently, the DS HE FSM is the appropriate structure which can be work"at fault circumstances due to dual excitations.

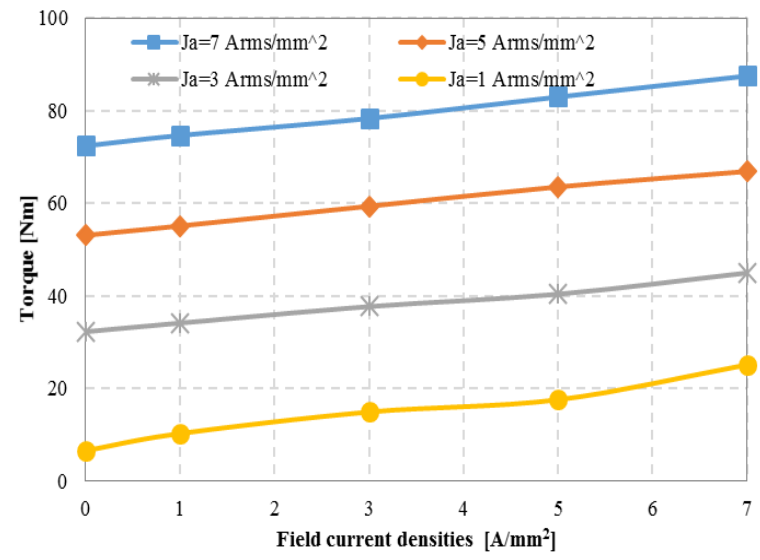

Fig. 8: Torque at various field current densities Je

\section{Torque and Power Vs Speed Characteristics of Initial Design}

Figure 9 illustrates the torque vs speed characteristics of the initial design of DS HESFM with segmental rotor. From the figure the blue and orange lines show the torque and power of the proposed design correspondingly. It is clear from the figure that

Initial design has achieved the maximum torque of $87.54 \mathrm{Nm}$ which is maintained until the speed of 5000rpm which is known as base speed. Furthermore, with the increase of speed the torque performance is reduced and reaches until $10 \mathrm{Nm}$ at maximum speed of 30,000rpm.

On the other hand, it is also obvious from figure that the initial design has achieved maximum power of $58.75 \mathrm{~kW}$ at speed of around $9000 \mathrm{rpm}$. However, with increase of speed the power graph is suddenly sags and reaches until $31.43 \mathrm{~kW}$ at maximum speed. The drop of power is due to the reason of core losses on the outer stator where field current produces the eddy current losses and results reduces the overall power at maximum speeds.

As a conclusion, the initial design of DS HEFSM has achieved satisfactory results of maximum torque at high speed ranges. It also verifies that proposed structure of DS HEFSM can be the favourite candidate for aircraft applications after modification and optimization, where high torque at high speeds is prerequisite requirement.

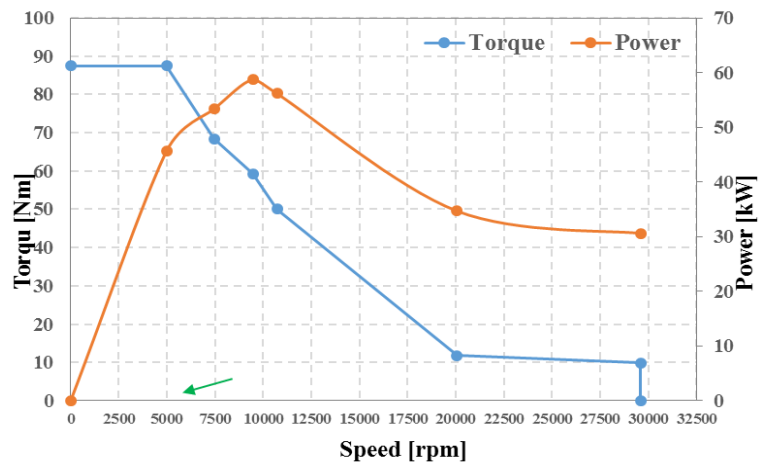

Fig. 9: Torque and power vs speed characteristics of initial DS HESFM 


\section{Conclusion}

The design challenges of DS HESFM for a directly driven EMA are investigated. Using separately excited double stator, a maximum chances of fault tolerance can be realized over suitable machine design and by accepting a suitable post-fault control approach. The performances of proposed design validates that the initial design has successfully achieved reasonable outcomes in terms of electromagnetic flux linkage generation, smooth flow of flux lines and high torque performance. Additionally, at open circuit or no load condition, cogging torque, back emf, electromagnetic flux lines and magnetic flux flow have been investigated to validate capability of new design to work at required safe regions. After the investigation of performances of new structure, it is obvious that the proposed design of HESFM with segmental rotor is suitable candidate to operate the electromechanical actuators to be used in aircraft applications at numerous speed regions. As the proposed motor deliver highest torque and power values at maximum speeds ranges, it can be used for different high speed applications. It is predicted that the magnetic flux and torque analysis of the proposed DS HESFM structure has viability to be further enhanced and optimised to achieve better performances.

\section{Acknowledgement}

This research work is fully promoted by "Research and Management center, University Tun Hussein Onn Malaysia (UTHM), and FRGS Grants Vote number 1651 and TIER Grant Vote number H083" under Ministry of Higher Education Malaysia (MOHE).

\section{References}

[1] Wenping. C, Mecrow B. C, Glynn J., John W. B, David J. A "Overview of Electric Motor Technologies Used for More Electric Aircraft (MEA)", IEEE Transactions on Industrial Electronics, Vol. 59, No.9, (2012), pp. 3523-3531.

[2] A. Boglietti, A. Cavagnino, A. Tenconi, and S. Vaschetto, "The safety critical electric machines and drives in the more electric aircraft: A survey", IEEE Conference of Industrial Electronics, (2009), pp. 2587-2594.

[3] C. Gerada, K. Bradley, C. Whitley, and G. Towers, "Integrated machine design for electro mechanical actuation," inProc. IEEE International Symposium on Industrial. Electronics. (2007), pp. 13051310.

[4] G. J. Atkinson, B. C. Mecrow, A. G. Jack, D. J. Atkinson, P. Sangha, and M. Benarous, "The analysis of losses in high-power faulttolerant machines for aerospace applications", IEEE Trans. Ind. Appl., Vol. 42, No. 5, (2006), pp. 1162-1170.

[5] G. J. Atkinson, B. C. Mecrow, A. G. Jack, D. J. Atkinson, P. Sangha, and M. Benarous, "The analysis of losses in high-power faulttolerant machines for aerospace applications", IEEE Trans. Ind. Appl., Vol. 42, No. 5, (2006), pp. 1162-1170.

[6] E. Levi, "Multiphase electric machines for variable-speed applications," IEEE Trans. Ind. Electron., vol. 55, no. 5, (2008), pp. 1893 1909.

[7] R. Kiani-Nezhad, B. Nehid-Mobarakeh, L. Baghli, F. Betin, and G.-A. Capolino, "Modeling and control of six-phase symmetrical induction machine under fault condition due to open phases," IEEE Trans. Ind. Electron., vol. 55, no. 5, (2008), pp. 1966-1977.

[8] B. C. Mecrow, A. G. Jack, D. J. Atkinson, S. R. Green, G. J. Atkinson, A. King, and B. Green, "Design and testing of a four-phase fault-tolerant permanent-magnet machine for an engine fuel pump," IEEE Trans. Energy Convers., vol. 19, no. 4, (2004), pp. 671-678.

[9] S. Bachir, S. Tnani, J.-C. Trigeassou, and G. Champenois, "Diagnosis by parameter estimation of stator and rotor faults occurring in induction machines," IEEE Trans. Ind. Electron., vol. 53, no. 3, (2006), pp. 963-973.

[10] X. Chang, V. Cocquempot, and C. Christophe, "A model of asynchronous machines for stator fault detection and isolation," IEEE Trans. Ind. Electron., vol. 50, no. 3, (2003), pp. 578-584.

[11] A. S. Goodman, K. J. Bradley, and P. W. Wheeler, "Evaluation of the single sided matrix converter driven switched reluctance mo- tor," int Conf. Rec. IEEE IAS Annu. Meeting, (2004), pp. 18471851.

[12] J. A. Haylock, B. C. Mecrow, A. G. Jack, and D. J. Atkinson, “Operation of fault tolerant machines with winding failures" IEEE Trans. Energy Convers., vol. 14, no. 4, pp. 1490-1495, Dec. 1999. 